Instruments to Assess Healthcare Interventions

NOTICE: This is the author's final version of a work that was accepted for publication in the journal Autism. Changes resulting from the publishing process, such as editing, corrections, formatting, and other quality control mechanisms may not be reflected in this document. The final, formatted version of this paper is available at https://doi.org/10.1177/1362361320967178

\title{
Psychometric testing of patient-reported instruments to assess healthcare interventions for
}

\section{autistic adults}

Christina Nicolaidis ${ }^{1,2,3,4}$, Kelly Y. Zhen ${ }^{1,4}$, Junghee Lee ${ }^{1}$, Dora M. Raymaker ${ }^{1,4}$, Steven K. Kapp $^{4,5}$ Lisa A Croen ${ }^{6}$, Anna Urbanowicz ${ }^{1,4,7}$, Joelle Maslak ${ }^{4}$, and Mirah Scharer ${ }^{1,4}$

${ }^{1}$ Regional Research Institute, School of Social Work, Portland State University (PSU), Portland, OR, USA

${ }^{2}$ Department of Medicine, Oregon Health \& Science University (OHSU), Portland, OR, USA

${ }^{3}$ OHSU-PSU School of Public Health, Portland, OR, USA

${ }^{4}$ Academic Autism Spectrum Partnership in Research and Education (AASPIRE), Portland, OR, USA

${ }^{5}$ Department of Psychology, University of Portsmouth, Portsmouth, UK

${ }^{6}$ Division of Research, Kaiser Permanente Northern California, Oakland, California, USA

${ }^{7}$ Social and Global Studies Centre, RMIT University, Melbourne, Australia 


\begin{abstract}
There is a growing recognition of the need for interventions to improve the healthcare of autistic adults. However, there is a dearth of validated measures to evaluate such interventions. Our objectives were to use a community based participatory research approach to create an accessible set of patient- and proxy-reported instruments to measure healthcare outcomes and potential intervention targets in autistic adults and to assess the instruments' psychometric characteristics, including content validity, construct validity, and internal consistency reliability. We administered a survey to 244 autistic adults recruited from 12 primary care clinics in Oregon and California, USA (194 participating directly, and 50 participating via a proxy reporter). Community partners ensured items were easy to understand and captured the intended construct. The AASPIRE Visit Preparedness Scale (VPS-6), Healthcare Accommodations Scale (HAS-8), and Patient-Provider Communication Scale (PPCS-8) were each found to have a single factor. The AASPIRE Health and Healthcare Self-Efficacy Scale (HHSE-21) had two factors: Individual Healthcare Self-Efficacy and Relationship-Dependent Healthcare Self-Efficacy. Both patientand proxy-report versions of all scales had good to excellent internal consistency reliability, with alphas ranging from 0.81 to 0.96 . The scales were associated with the Barriers to Healthcare Checklist and the Unmet Healthcare Needs Checklist in the hypothesized directions.
\end{abstract}

Keywords: autism, adults, healthcare, community-based participatory research, patientreported outcome measures, psychometrics 
Instruments to Assess Healthcare Interventions

Psychometric testing of a set of patient-reported instruments to assess healthcare interventions for autistic adults

Numerous studies have shown that autistic adults experience significant health and healthcare disparities. Specifically, autistic adults have more frequent co-occurring physical and mental health conditions (Croen et al., 2015; Fortuna et al., 2016) with higher rates of premature mortality (Hirvikoski et al., 2016) and inpatient mortality (Akobirshoev, Mitra, Dembo, \& Lauer, 2019). They also have greater overall healthcare utilization and costs (Zerbo et al., 2019) and higher use of the emergency department (Nicolaidis et al., 2013; Vohra, Madhavan, \& Sambamoorthi, 2016), with lower use of recommended preventative services, such as Papanicolaou smears (Nicolaidis et al., 2013; Zerbo et al., 2019). Similarly, studies focused on quality of care have found that autistic adults have greater unmet healthcare needs, lower satisfaction with patient provider communication, and more barriers to care than non-autistic adults (Mason et al., 2019; Nicolaidis et al., 2013; Raymaker et al., 2017).

As such, there have been many calls for interventions to improve the health and healthcare of autistic adults (Barber, 2017; Hall, Kriz, Duvall, Nguyen-Driver, \& Duffield, 2015; Liu, Pearl, Kong, Leslie, \& Murray, 2017; Nicolaidis, Kripke, \& Raymaker, 2014; Zerbo, Massolo, Qian, \& Croen, 2015). However, this field is still in its infancy, with few evidence-based interventions to improve care (Mason et al., 2019). An important early step in creating effective interventions entails identifying potential intervention targets (also known as mechanisms of action). Our prior qualitative studies and pilot intervention evaluation suggested that interventions aimed at improving healthcare for autistic adults may do so by helping patients better prepare for visits, increasing patient and provider self-efficacy, and increasing the use of necessary accommodations in healthcare (Nicolaidis et al., 2016; Nicolaidis et al., 2015).The next step is identifying instruments to validly measure both the desired healthcare outcomes and potential intervention targets. However, there is a dearth of validated measures for use with 
Instruments to Assess Healthcare Interventions

individuals on the autism spectrum (U.S. Department of Health and Human Services, 2017). Most existing health services measures have not been tested for use with autistic adults. The use of such measures, without adequate adaptation or testing, may significantly weaken the rigor of intervention evaluations given autistic adults' impressions that existing instruments may not be accessible, may not fully capture the intended constructs, and may cause confusion, anxiety, frustration, or anger (Nicolaidis et al., 2019).

Our objectives were to use a Community Based Participatory Research (CBPR) approach to create a set of accessible patient- or proxy-report instruments to be used in research aimed at improving healthcare for autistic adults and to assess their preliminary psychometric properties, including content validity, construct validity, and internal consistency reliability. Given what is already known about the existence of healthcare disparities for autistic adults, and the urgent need for interventions, these instruments focus on healthcare outcomes -- including patient-provider communication, barriers to healthcare, and unmet healthcare needs--and potential intervention targets -- including healthcare self-efficacy, visit preparedness, and provider-and-staff use of accommodations.

\section{Methods}

\section{Community-Academic Partnership}

The Academic Autism Spectrum Partnership in Research and Education (AASPIRE;

www.aapire.org) is a long-standing community-academic partnership that has been using a CBPR approach since 2006 . The team includes academics, autistic adults, family members, healthcare providers, and disability services providers, some of whom have overlapping roles. Academic and community partners collaborated as equal partners throughout the project to 1) make decisions about the research questions and study design using a consensus process; 2) co-create consent and recruitment materials; 3) adapt existing instruments; 4) create new data collection instruments; 5) 
Instruments to Assess Healthcare Interventions

interpret data; and 6) co-author this manuscript. Our community partners were instrumental in ensuring that study questions were relevant to the autistic community and that materials, including survey instruments, used accessible language, were easy to complete, fully addressed the intended construct, and were as respectful as possible. Further details about our collaboration processes are available elsewhere (Nicolaidis et al., 2019; Nicolaidis et al., 2011).

\section{Conceptual Model}

We used our prior survey studies (Nicolaidis et al., 2013; Raymaker et al., 2017), qualitative research (Nicolaidis et al., 2015), and intervention pilot-testing (Nicolaidis et al., 2016) to create a model that explains how interventions may theoretically improve care and reduce known healthcare disparities experienced by autistic adults (Figure 1). We then set out to use, adapt, or create instruments to measure each of the constructs in the model. This paper focuses on the constructs that are measured by patient or proxy report. Another paper discusses constructs that are reported by healthcare providers <under review for this special issue>. Future work will explore the relationship between these measures, healthcare utilization, and health, and will assess how interventions may affect these constructs.

\section{Setting}

This analysis uses baseline data from a study to integrate the AASPIRE Healthcare Toolkit into three healthcare systems in the United States. The study took part in 1) eight primary care clinics that are part of a large integrated healthcare system in California; 2) two primary care clinics affiliated with an academic medical center in Oregon; and 3) two primary care clinics affiliated with a private health system in Oregon. The project was approved by the institutional review boards of our university and each health system.

\section{Participants, recruitment, and data collection}


Instruments to Assess Healthcare Interventions

Eligible participants were adults (age 18 and up) with diagnoses of autism spectrum disorder (including autistic disorder, Asperger's disorder, and pervasive developmental disorder--not otherwise specified), who obtained primary care from the participating clinics. In cases where patients could not participate directly, even with appropriate accommodations and supports, we asked a supporter to participate as a proxy reporter with as much input as possible from the autistic patient. Each health system identified all adult patients assigned to the participating practices who had an ICD-9 or 10 code in their records consistent with autism (299.00, 299.8, and 299.9 or F84.0, F84.5, and F84.9). Staff from the partnering health systems sent a letter (via mail or secure electronic health record message) to potential participants inviting them to the study, and followed up with telephone calls. In Oregon, where the partnering clinics only had a small number of adult autistic patients, clinic staff invited all eligible participants. In California, research staff randomly selected batches of approximately 700 participants to invite at a time, over-sampling participants of color (African American, Latinx, Asian, Native American, or mixed race). They invited additional batches of participants until our recruitment targets were met.

Our consent process followed the AASPIRE Guidelines for the Inclusion of Autistic Adults in Research (Nicolaidis et al., 2019). Participants could provide informed consent over the internet, telephone or in person. The consent process started with a series of questions to assess if the person was taking part on their own, with support, or via a proxy reporter. In cases where the participant accessed and participated in the survey on their own over the internet, we did not assess for decisional capacity, given that this study posed minimal risk and participants who use the Internet independently likely make decisions with equal or greater risk on a regular basis. In cases where they participated independently by telephone or in person, we instructed the interviewer to assess for decisional capacity if the interaction raised any concern about decisional impairment. When a supporter was involved (either to provide support or serve as a proxy reporter), we asked a series of questions to understand if the participant generally makes the types of decisions involved in this study themselves or via a legally 
Instruments to Assess Healthcare Interventions

authorized representative (LAR). If they made these decisions themselves, we asked the supporter to help the participant, as needed, to read and understand the information and communicate their decision to us. In cases where a participant could not offer informed consent, even with support, we asked for consent from a LAR. In some cases, the LAR was the same person that was providing support or serving as a proxy reporter; when it was not, we contacted the LAR to obtain consent prior to continuing with the survey.

We created a survey that included measurements for each of the patient- or proxy- reported constructs in our model. We created two versions of the survey - one for use with autistic adults directly (with or without help from a supporter) and another for use by proxy reporters. We administered the survey online, in person, or via telephone to 244 autistic adults ( $17 \%$ response rate). The vast majority participated in the survey online. One hundred and ninety-four participated directly (with or without support), and 50 participated via a proxy reporter. Autistic patients had a mean age of 30 years (range 18-72); $70 \%$ were male; and $62 \%$ were non-Hispanic white. Thirty-nine percent often or always, $24 \%$ sometimes, and $38 \%$ rarely or never needed assistance in healthcare settings. Thirty-eight percent reported a co-occurring chronic physical health condition, and $61 \%$ reported a co-occurring mental health condition. Table 1 presents characteristics of patients who participated directly (with or without help from a supporter) and those who participated via a proxy reporter.

\section{Measures}

The baseline survey included each of the 6 measures discussed in this paper (Table 2), as well as additional items on demographic and disability-related characteristics.

We assessed unmet healthcare needs, using a checklist we previously adapted from the 2002/2003 Joint US Canada Survey (Blackwell, 2004; Sanmartin et al., 2006). The item states “During the past 6 months, there was a time when I felt that I needed the following type of healthcare, but did not 
Instruments to Assess Healthcare Interventions

receive it. (Check all that apply)." Response options include six types of healthcare (e.g., "medical care for a physical health problem," "mental healthcare or counseling"). As we have done in prior studies (Nicolaidis et al., 2013) we dichotomized results to separate participants that did or did not have any unmet healthcare needs and created a proxy version that asked the items in the third person.

We assessed barriers to healthcare using the Barriers to Healthcare Checklist: Short Form (Raymaker et al., 2017). The checklist includes 16 barriers commonly experienced by autistic patients. It is scored as a count of the total number of barriers endorsed. As this count data was highly skewed, we dichotomized results at the top quartile to identify participants with high barriers to care (i.e. 0-3 barriers vs 4 or more barriers). The original instrument only included a patient-version. We created a proxy version for use in a prior study (Nicolaidis et al., 2016).

We collected data on satisfaction with patient provider communication using the AASPIRE Patient-Provider Communication Scale (PPCS-8). This scale is a highly adapted version of items from the 2007 Health Information National Trends Survey (HINTS)(Cantor, 2009; Hong, 2008; Marks, Ok, Joung, \& Allegrante, 2010; Ok, Marks, \& Allegrante, 2008). Using our CBPR instrument adaptation process, we added a preface and clarified some wording to increase accessibility, made wording modifications to allow for self-report, and added two new items on expressive and receptive communication. We used the adapted scale, which asked participants to think of healthcare interactions over the past 12 months, in our health care survey (Nicolaidis et al., 2013). We used it again in our intervention pilot-test (Nicolaidis et al., 2016), but based on community partner feedback, we changed the preface to ask participants to think about their last visit with their primary care provider and, accordingly, changed response options from the original 4-point Likert scale that had anchors of "Never" to "Always" to a 5point Likert scale with anchors of "Strongly disagree" to "Strongly agree." We also created a proxyreport version of the scale. We used this version of the scale in the current study with no further 
Instruments to Assess Healthcare Interventions

adaptations. The final 8-item scale can range from 8 to 40, with higher scores indicating higher satisfaction with patient-provider communication. A ninth item asking about overall satisfaction with healthcare was not included in these analyses.

We measured healthcare self-efficacy using the AASPIRE Health and Healthcare Self-Efficacy Scale (HHSE-21). Our community-academic team had previously co-created the self-report and proxy versions of this measure, de novo, for use in our intervention pilot-testing study (Nicolaidis et al., 2016). Constructs are based on a review of the literature, data from our prior survey and qualitative research, and on the team's lived experience. We made additional adaptations to that measure based on partner and participant feedback and included it in this study. The 21-item scale has response options that use a 10-point Likert scale with anchors of $0=$ Not at all confident to $10=$ Totally confident. The scale is scored by adding responses, and then dividing the sum by the number of items. The resulting scale has a possible range of 1-10, with higher scores corresponding to higher self-efficacy. As below, factor analysis identified two subscales, so the remaining analyses were conducted using the two separate subscales.

We co-created two additional scales to cover constructs that had emerged from our prior qualitative work as potential intervention targets, namely visit-preparedness and use of healthcare accommodations. The AASPIRE Visit Preparedness Scale (VPS-6) is a 6-item measure. Response options use a 5-point Likert scale anchored at $1=$ Strongly disagree and $5=$ Strongly agree. The scale is scored by summing the individual items. It has a range of 6-30, with higher scores indicating higher visit preparedness. The AASPIRE Healthcare Accommodations Scale (HAS-8) measures patient's perspectives on how well their accommodation needs are being met by healthcare providers and other clinic staff. Result options use a 5-point Likert scale with anchors of $1=$ Strongly disagree and $5=$ Strongly agree. Scores from the eight items are summed. The resulting scale can range from 8 to 40, with higher scores indicating higher use of accommodations. Two open-ended items ask participants to describe what 
Instruments to Assess Healthcare Interventions

accommodations they receive and what additional accommodations they would want. Each instrument has a self-report and proxy version.

\section{Data Analysis}

We based our psychometric testing on the COSMIN (COnsensus-based Standards for the selection of health Measurement Instruments) Initiative's international consensus on the taxonomy, terminology, and definitions of measurement properties for health-related patient-reported outcomes (Mokkink et al., 2010). We assured content validity for all six instruments by working closely with our academic and community partners, including autistic adults, family members, and healthcare providers. We reviewed each draft instrument with our community partners and discussed their impressions, including whether the items were easy to understand, if they were addressing the intended constructs, and if they included all important aspects of the constructs. We kept written transcripts of community partner meetings, summarized recommendations, and made adaptations to draft scales as needed.

We assessed one type of reliability (internal consistency reliability) and two aspects of construct validity (structural validity and hypothesis testing about expected associations). Four of the measures included in this study (patient-provider communication, visit preparedness, use of accommodations, and healthcare self-efficacy) are multi-item scales, where individual items use Likert-style response options. For these measures, summary scores approximate a normal distribution. Thus, these four measures were conducive to assessment of internal consistency reliability and structural validity. The other two measures (unmet needs and barriers to care) used a checklist format, which resulted in a series of multiple dichotomous variables (six variables indicating the presence or absence of each unmet need and 16 variables indicating the presence or absence of each barrier). Counts of unmet needs or barriers to care do not approximate a normal distribution. As such, we created two dichotomous variables - any unmet needs and 4 or more barriers to care. We used all six instruments in testing a priori hypotheses 
Instruments to Assess Healthcare Interventions

about expected associations, another important aspect of construct validity. We did not assess criterion validity or responsiveness to change.

We tested the structural validity for each of the four scored scales by conducting Principal Axis Factor Analyses (PAF). We used the Kaiser-Meyer-Olkin (KMO) Measure and Bartlett's Test of Sphericity (Green \& Salkind, 2013) to verify sampling adequacy for factor analysis. We expected the KMO statistics to be 0.7 or higher and Bartlett's test to be significant in order to proceed with factor analysis. We used three criteria to determine factor structure: Kaiser's recommendation of eigenvalues over 1, a scree plot which we used to visualize the eigenvalues, and the interpretability of the factor communalities if the two criteria give different results (Green \& Salkind, 2013). If these three criteria indicated our initial hypothesis of unidimensionality was incorrect, we rotated factors using the Varimax procedure (Green \& Salkind, 2013) in order to make the factors more interpretable, and to make final decisions about underlying factors. We tested two groups of study participants (i.e., those who participated directly and those who participated via proxy) separately and found no structural differences between the two groups. Thus, we conducted factor analyses with all participants combined. We only had a small amount of missing data (between $2 \%-6.1 \%$ per each item), so we used listwise deletion to handle missing data. We assessed internal consistency reliability for each scored scale or subscale using Cronbach's alpha.

We further examined construct validity for all measures by testing a-priori hypotheses about expected association using pair-wise correlations and t-tests. Specifically, we hypothesized that each of intervention targets (visit preparedness, provider/staff use of accommodations, and individual and relational healthcare self-efficacy) would be positively correlated with satisfaction with patient-provider communication. We also hypothesized that participants who reported four or more barriers to care or any unmet healthcare needs would have lower scores on each of the intervention targets that those who did not. 
Instruments to Assess Healthcare Interventions

We conducted secondary analyses stratifying data from those who participated directly (with or without help from a supporter) and those who participated via a proxy reporter. Given the small number of patients who participated via a proxy reporter, those findings should be interpreted with caution.

\section{Access to Research Materials}

The full text and scoring instructions for each of the six instruments are included in Table 2. Per $\mathrm{NIH}$ guidelines, we have deposited the underlying data in the National Data Archive.

\section{Results}

\section{Content Validity}

Academic and community partners carefully reviewed all instruments. They felt items were easy to understand, easy to answer, and fully captured the intended construct.

\section{Structural Validity}

KMO Test scores were $.774, .922, .943$, and .922 for the Visit Preparedness Scale, the Provider and Staff Use of Accommodations Scale, the Patient-Provider Communication Scale, and the Health and Healthcare Self-Efficacy Scale, respectively. KMO statistics fell into the range of good (0.7) to superb (.9 or above), indicating that our sample size was adequate for factor analysis (Hutcheson \& Sofroniou, 1999). Bartlett's Test of Sphericity was also significant $(p<.001)$ for each of the scales, further confirming sampling adequacy.

PAF analyses indicated that the Visit Preparedness Scale, the Provider and Staff Use of Accommodations Scale, and the Patient-Provider Communication Scale each had a single factor with sufficient factor loadings $(0.68-0.88,0.61-0.75,0.76-0.86$ respectively) and explained variance of $46.94 \%, 64.33 \%$, and $66.36 \%$ respectively. 
Instruments to Assess Healthcare Interventions

On the other hand, the assessment of eigenvalues and scree plots, as well as the extracted communalities, indicated the Health and Healthcare Self-Efficacy Scale had a two-factor structure with $49.63 \%$ of explained variance. The initial factor loadings ranged between 0.35 to 0.86 . In consideration of our sample size $(n=244)$, all factor loadings were adequate (Stevens, 2012) for further factor analysis. Factor loadings from the Varimax rotation procedure are shown in Table 3.

Academic and community partners reviewed which items loaded best on each subscale and discussed what, conceptually, may differentiate the two groups. The group concluded that while all items related to self-efficacy, one set of items primarily related to aspects of care that a patient (or supporter) could control by themselves (e.g. making an appointment, tolerating a procedure, taking prescribed medications), while the other group of items depended not only on the patient, but also on the provider, staff, or healthcare system (e.g., communicating with provider, being included in decisionmaking). Based on this discussion, we entitled the subscales: Individual Healthcare Self-Efficacy and Relationship-Dependent Healthcare Self-Efficacy. Three items loaded very similarly to both factors: taking part in healthcare decisions (loading of 0.48 on both factors); changing healthcare providers (loading of 0.35 on both factors), and getting necessary accommodation (loading of 0.49 vs 0.54 with the relationship vs individual skill-based efficacy respectively). Our academic and community partners felt these three items were conceptually more relevant with relationship-dependent healthcare self-efficacy skills than the individual-healthcare self-efficacy, so we included them with the former scale.

\section{Internal Consistency Reliability}

The Visit Preparedness Scale, the Healthcare Accommodations Scale, and the Patient-Provider Communication Scale each had good to excellent internal consistency reliability (Cronbach alpha $=.85$, $.93, .95$ respectively). Both subscales of the Health and Healthcare Self-Efficacy scale also had good to 
Instruments to Assess Healthcare Interventions

excellent reliability (Cronbach alpha $=.88$ for the Individual and .92 for the Relationship-Dependent Healthcare Self-Efficacy subscales; see Table 4).

\section{Testing of Hypothesized Associations}

Hypothesis testing demonstrated significant associations in the expected directions. Participants who reported unmet healthcare needs had lower confidence in individual and relationship dependent healthcare self-efficacy, felt less prepared for healthcare visits, and were less likely to receive necessary accommodations. The same held true for patients who reported 4 or more barriers to care. There were strong positive correlations between satisfaction with patient-provider communication and individual healthcare self-efficacy, relationship-dependent healthcare self-efficacy, visit preparedness, and use of accommodations (Table 5). Secondary analyses limited to the sample of those who participated directly were very similar. In the analysis limited to people who participated via proxy, associations were qualitatively similar, but on a few occasions, they did not reach statistical significance due to the small sample size (data not shown).

\section{Discussion}

Our CBPR team assembled a package of patient- or proxy-reported instruments to be used in evaluating health services interventions for autistic adults. Our preliminary psychometric testing offers support of their content validity, construct validity, and internal consistency reliability.

Patient-provider communication is a key construct throughout the health services literature, with studies in the general populations showing a correlation between effective physician-patient communication and improved patient health outcomes (Stewart, 1995). However, when the autistic members of our team reviewed existing measures of satisfaction with patient-provider communication, they consistently felt they were inaccessible or incomplete. The PPCS-8, created by collaboratively adapting items from the 2007 Health Information National Trends Survey (HINTS)(Cantor, 2009; Hong, 
Instruments to Assess Healthcare Interventions

2008; Marks et al., 2010; Ok et al., 2008), allows researchers to assess this important construct in autistic adults. Our prior two studies had shown that the scale has strong internal consistency reliability in two separate samples (Nicolaidis et al., 2013; Nicolaidis et al., 2016), and was responsive to change (Nicolaidis et al., 2016). The current study confirms the scale's excellent internal consistency reliability in a third sample, while also providing new data on its construct validity.

Similarly, the concept of patient self-efficacy is ubiquitous throughout health services research. However, most existing measures are disease specific (Clay \& Telfair, 2007; Shively, Smith, Bormann, \& Gifford, 2002), focus on self-management of chronic illnesses (Du \& Yuan, 2010), or primarily address self-care (Callaghan, 2003). Our team did not feel that existing instruments, even with adaptations for accessibility, would capture the aspects of health and healthcare self-efficacy that were most important to autistic adults. We thus co-created a self-efficacy instrument based on our prior studies (Nicolaidis et al., 2013; Nicolaidis et al., 2015; Raymaker et al., 2017) and the lived experience of the autistic adults, healthcare providers, and supporters on our CBPR team. Our prior work found that an earlier version of this scale had excellent internal consistency reliability and was responsive to change (Nicolaidis et al., 2016). This study confirms the scale's internal consistency reliability and adds support for its construct validity. Interestingly, while we originally thought of items as addressing healthcare (e.g., navigating the healthcare system or communicating with a provider) versus health (e.g., living a healthy lifestyle or managing one's chronic medical issues), exploratory factor analyses found that the scale had two different factors: Individual Healthcare Self-Efficacy (i.e. aspects that a patient or supporter can control by themselves) and Relationship-Dependent Healthcare Self-Efficacy (i.e. aspects that depend not only on the patient, but also on the provider, staff, or healthcare system). Researchers who use the scale should score these two subscales separately.

While visit preparedness may be an aspect of healthcare self-efficacy (and the HHSES-21 includes one item about it), the importance of visit preparedness was such a strong theme in our prior 
Instruments to Assess Healthcare Interventions

qualitative data (Nicolaidis et al., 2016) that our team created a separate multi-item measure for this construct. The new VPS-6 addresses aspects of visit preparedness such as if a patient brought what was needed to the visit, came prepared with a list of topics to discuss, felt ready to discuss their symptoms and answer the provider's questions, and knew what to expect from the appointment and their provider. As opposed to self-efficacy instruments, which focus on whether a patient feels confident that they can do what is needed, this instrument asks about what actually happened at the patient's last visit. We found the new scale had strong internal consistency reliability and construct validity. It may provide additional depth to evaluations of interventions that target patients' visit preparedness as a mechanism for improving healthcare.

Many calls for improved healthcare for autistic adults have also focused on the need for health systems and individual providers to make necessary accommodations (Mason et al., 2019). We previously created the Autism Healthcare Accommodations Tool (AHAT) to help patients communicate their accommodation needs to healthcare providers (Nicolaidis et al., 2016). Other studies have focused on the importance of accommodations in healthcare settings for people with mobility impairments (Pharr, 2014; Pharr, James, \& Yeung, 2019) or communication disorders (Burns, Baylor, Dudgeon, Starks, \& Yorkston, 2017), but such studies relied on survey data from healthcare administrators or providers or only collected qualitative data. The new HAS-8 showed strong internal consistency reliability and construct validity. To our knowledge, this is the first instrument in the literature that assesses if patients feel their healthcare accommodation needs are actually met.

Though this paper focuses primarily on the psychometric properties of the four scored scales, it also included two additional checklists, the Barriers to Healthcare Checklist and the Unmet Healthcare Needs Checklist in hypothesis testing. The concept of "barriers to care" is ubiquitous throughout the health services literature, but assessment of barriers to care requires understanding the specific issues that may be pertinent to a particular patient population or health condition. For example, disease- 
Instruments to Assess Healthcare Interventions

specific systematic reviews exist on barriers to the identification and treatment of hypertension (Khatib et al., 2014), vaccination against human papilloma virus (Holman et al., 2014), or to testing for HIV (Deblonde et al., 2010); and population-specific systematic reviews exist on barriers to healthcare for undocumented immigrants (Hacker, Anies, Folb, \& Zallman, 2015), patients in rural areas (Brundisini et al., 2013), and indigenous people with chronic diseases (Gibson et al., 2015). When we originally tried to assess barriers to general healthcare for autistic adults, there were no published studies on this topic. As such, we started with an unpublished barriers to healthcare checklist that had been created for people with disabilities in general, and worked with our community partners to ensure that it was accessible to autistic adults and that it included additional barriers may be particularly relevant to autistic populations (e.g. sensory or communication-related barriers). We tested the resulting instrument, the Barriers to Healthcare Checklist - Long Form, in an online sample of autistic adults and adults with and without other disabilities (Raymaker et al., 2017); collapsed items to create the Barriers to Healthcare Checklist Short Form; and used the Short Form in our prior pilot intervention, where we found it was responsive to change (Nicolaidis et al., 2016). The current study further demonstrates the instrument's construct validity in a separate sample. Similarly, we have now used the Unmet Healthcare Needs Checklist in three separate samples of autistic adults (Nicolaidis et al., 2013; Nicolaidis et al., 2016), and have found it to be easy to answer and be associated in the expected directions with other healthcare measures.

We believe our use of a CBPR approach strengthened this project in many ways. First, autistic adults, supporters, and healthcare providers helped identify what constructs were most important to measure and helped create a model for how interventions may improve healthcare for autistic adults. Second, these community partners helped ensure construct validity for all measures, with special attention on creating instruments that are easy to understand, that can be answered easily without undue participant burden or frustration, that are applicable to real-life healthcare settings, and that are comprehensive and respectful. And finally, community partners played a critical role in interpreting 
Instruments to Assess Healthcare Interventions

findings - for example in helping understand what may conceptually differentiate the two factors on the HHSES-21.

We created this set of instruments for use in our own healthcare studies because there were no other validated measures to assess these constructs in autistic adults. However, we believe this set of measures may be useful to other autism researchers seeking instruments that have been validated with autistic populations. Use of this set of instruments may also help compare experiences of autistic adults in different health systems or countries. Researchers using these instruments with other autistic populations, especially in other countries, should assess for the need of adaptations and recheck psychometric properties.

While we created this set of instruments for use with autistic adults, the constructs themselves are not autism-specific and none of the items specifically mention autism. Adaptations of prior instruments focused on making the language clearer and more specific or increasing completeness by adding new items. Moreover, we created the new instruments on visit preparedness and use of accommodations because we were unable to find any patient-reported measures for these constructs, even for other populations. This set of measures may potentially be useful in evaluating health services interventions in general populations or in patients with other disabilities or health conditions. However, future research is needed to establish the psychometric properties of these instruments in other populations.

Our study has several limitations. First, this analysis only uses cross-sectional data, so it is not intended to assess causative relationships or responsiveness to change. Similarly, this analysis only focuses on patient- or proxy-reported data and does not correlate findings with data from other sources. Future research is needed to assess how well these instruments capture intervention effects, or to triangulate findings with healthcare utilization data. The low response rate may have introduced participation bias. Moreover, we only included a small number of participants who relied on proxy 
Instruments to Assess Healthcare Interventions

reporters. We believe that offering the survey in various modes was critical to including participants with different accommodation needs; however, we did not have a large enough number of participants taking part over the telephone or in person to allow for comparison of results by data collection mode. Additional research is needed to validate the proxy-report versions of these instruments. Finally, while our study was strengthened by the inclusion of patients from three different health systems, further research is needed to validate these instruments outside of the United States or to translate the measures for non-English-speaking populations.

\section{Conclusions}

The new measures demonstrated strong content validity, construct validity, and internal consistency reliability. Future research is needed to 1) further validate these scales, especially in patients who participate via proxy; 2 ) assess their responsiveness to change; 3 ) assess whether interventions improve healthcare outcomes; and 4) test whether they do so via these hypothesized mechanisms of action.

\section{Acknowledgements}

We would like to thank the entire AASPIRE team for their significant contributions throughout this project. We also are grateful to the skilled research staff at Kaiser Permanente of Northern California; all the participants who volunteered to be in this study; and the people who supported them. This study was funded by the National Institute of Mental Health (R34MH111536; PI: Nicolaidis). The content is solely the responsibility of the authors and does not necessarily represent the official views of the National Institutes of Health. 
Instruments to Assess Healthcare Interventions

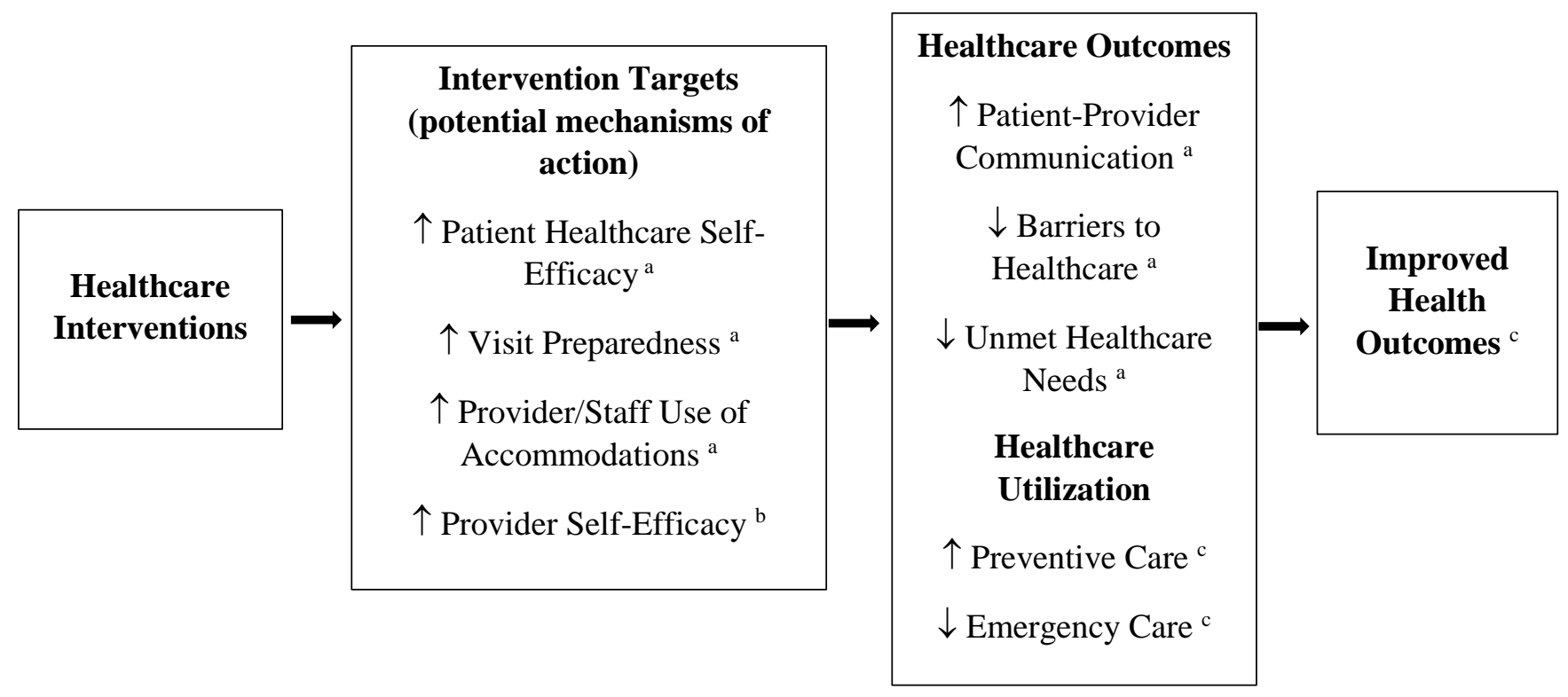

Figure 1. Theoretical Model for How Healthcare Interventions May Improve Outcomes

Notes:

${ }^{\text {a }}$ Patient- or proxy-report; discussed in this paper

${ }^{\mathrm{b}}$ Provider-report; discussed in separate paper.

${ }^{\mathrm{c}}$ To be assessed in future research. 
Instruments to Assess Healthcare Interventions

Table 1

Participant Characteristics

\begin{tabular}{|c|c|c|c|}
\hline Characteristic & $\begin{array}{c}\text { Total Sample } \\
(\mathrm{N}=244) \\
\text { mean (range) or } \\
\mathrm{N}(\%)\end{array}$ & $\begin{array}{c}\text { Participated } \\
\text { directly ( } \mathrm{N}=194) \\
\text { mean (range) or } \\
\mathrm{N}(\%)\end{array}$ & $\begin{array}{c}\text { Participated via } \\
\text { Proxy ( } \mathrm{N}=50) \\
\text { mean (range) or } \\
\mathrm{N}(\%)\end{array}$ \\
\hline \multicolumn{4}{|l|}{ Age } \\
\hline & $30.22(18-72)$ & $30.69(18-72)$ & $28.42(18-68)$ \\
\hline \multicolumn{4}{|l|}{ Gender } \\
\hline Male & $168(70 \%)$ & $131(69 \%)$ & $37(74 \%)$ \\
\hline Female & $68(28 \%)$ & $55(29 \%)$ & $13(26 \%)$ \\
\hline Other & $5(2 \%)$ & $5(3 \%)$ & 0 \\
\hline \multicolumn{4}{|l|}{ Race/Ethnicity } \\
\hline Non-Hispanic White & $147(62 \%)$ & $134(71 \%)$ & $13(27 \%)$ \\
\hline Black/African American & $24(10 \%)$ & $6(3 \%)$ & $18(37 \%)$ \\
\hline Asian/Pacific Islander & $18(8 \%)$ & $14(7 \%)$ & $4(8 \%)$ \\
\hline Biracial/other & $22(9 \%)$ & $15(8 \%)$ & $7(14 \%)$ \\
\hline Latino & $28(12 \%)$ & $21(11 \%)$ & $7(14 \%)$ \\
\hline \multicolumn{4}{|l|}{ Education Level } \\
\hline Less than High School & $34(14 \%)$ & $7(4 \%)$ & $27(55 \%)$ \\
\hline Modified High School Diploma & $28(12 \%)$ & $12(6 \%)$ & $16(33 \%)$ \\
\hline Regular High School Diploma & $20(8 \%)$ & $20(11 \%)$ & 0 \\
\hline Some College (no degree) & $81(34 \%)$ & $76(40 \%)$ & $5(10 \%)$ \\
\hline Associates & $20(8 \%)$ & $19(10 \%)$ & $1(2 \%)$ \\
\hline Bachelors & $43(18 \%)$ & $43(23 \%)$ & 0 \\
\hline Masters/Graduate Certificate & $12(5 \%)$ & $12(6 \%)$ & 0 \\
\hline \multicolumn{4}{|l|}{ Residence } \\
\hline Place they own or rent & $74(31 \%)$ & $64(34 \%)$ & $10(20 \%)$ \\
\hline With Family & $161(67 \%)$ & $121(64 \%)$ & $40(80 \%)$ \\
\hline Other & $4(2 \%)$ & $4(2 \%)$ & 0 \\
\hline \multicolumn{4}{|l|}{ Needs Assistance in Healthcare Setting } \\
\hline Always or Often & $86(39 \%)$ & $37(22 \%)$ & $49(98 \%)$ \\
\hline Sometimes & $52(24 \%)$ & $51(30 \%)$ & $1(2 \%)$ \\
\hline Rarely or Never & $83(38 \%)$ & $83(49 \%)$ & 0 \\
\hline \multicolumn{4}{|l|}{ Communication with Providers } \\
\hline I communicate with providers myself & $104(44 \%)$ & $101(54 \%)$ & $3(6 \%)$ \\
\hline $\begin{array}{l}\text { I mostly communicate with providers myself, } \\
\text { but someone helps some of the time }\end{array}$ & 78 (33\%) & 70 (37\%) & $8(16 \%)$ \\
\hline & $56(24 \%)$ & $17(9 \%)$ & $39(78 \%)$ \\
\hline
\end{tabular}


Instruments to Assess Healthcare Interventions

\begin{tabular}{|c|c|c|c|}
\hline Talk & $199(83 \%)$ & $179(95 \%)$ & $20(40 \%)$ \\
\hline Something Else & $13(5 \%)$ & 7 (4\%) & $6(12 \%)$ \\
\hline N/A & $27(11 \%)$ & $3(2 \%)$ & $24(48 \%)$ \\
\hline \multicolumn{4}{|l|}{ Self-Reported Health Status } \\
\hline Poor & $10(4 \%)$ & $8(4 \%)$ & $2(4 \%)$ \\
\hline Fair & $38(16 \%)$ & 32 (17\%) & $6(12 \%)$ \\
\hline Good & $78(33 \%)$ & $61(32 \%)$ & $17(34 \%)$ \\
\hline Very Good & $78(33 \%)$ & $63(33 \%)$ & $15(30 \%)$ \\
\hline Excellent & $35(15 \%)$ & $25(13 \%)$ & $10(20 \%)$ \\
\hline \multicolumn{4}{|l|}{ Chronic Health Condition } \\
\hline & $141(61 \%)$ & $115(63 \%)$ & $26(52 \%)$ \\
\hline \multicolumn{4}{|l|}{ Mental Health Condition } \\
\hline & $89(38 \%)$ & $69(38 \%)$ & $20(40 \%)$ \\
\hline \multicolumn{4}{|l|}{ Insurance Type } \\
\hline Private Insurance & $160(72 \%)$ & $128(75 \%)$ & $32(64 \%)$ \\
\hline Government Insurance & $61(28 \%)$ & $43(25 \%)$ & $18(36 \%)$ \\
\hline
\end{tabular}


Instruments to Assess Healthcare Interventions

Table 2

Healthcare instruments included in the survey

\begin{tabular}{|c|c|c|c|}
\hline \multicolumn{4}{|c|}{ Multi-Item Scales } \\
\hline Survey Instrument & Item $(\mathrm{s})^{*}$ & Response options & Scoring \\
\hline $\begin{array}{l}\text { AASPIRE Patient- } \\
\text { Provider } \\
\text { Communication } \\
\text { Scale (PPCS-8) }\end{array}$ & $\begin{array}{l}\text { For the next set of questions, think about the last visit you had with your primary } \\
\text { care provider. } \\
\text { 1. My primary care provider gave me the chance to ask all the health-related } \\
\text { questions I had. } \\
\text { 2. My primary care provider gave the attention I needed to my feelings and } \\
\text { emotions. } \\
\text { 3. My primary care provider involved me in decisions about my healthcare as } \\
\text { much as I wanted. } \\
\text { 4. My primary care provider made sure I understood the things I needed to do } \\
\text { to take care of my health. } \\
\text { 5. My primary care provider helped me deal with feelings of uncertainty about } \\
\text { my health or healthcare. } \\
\text { 6. My primary care provider understood what I was trying to communicate. } \\
\text { 7. My primary care provider communicated in a way that I could understand. } \\
\text { 8. I felt I could trust my primary care provider to take care of my healthcare } \\
\text { needs. }\end{array}$ & $\begin{array}{l}\text { Strongly disagree } \\
=1 ; \text { disagree=2; } \\
\text { neither agree nor } \\
\text { disagree=3; } \\
\text { agree }=4 \text {; strongly } \\
\text { agree }=5\end{array}$ & $\begin{array}{l}\text { This scale is } \\
\text { scored by } \\
\text { summing } \\
\text { responses the } 8 \\
\text { items. Scores } \\
\text { range from } 8 \text { to } \\
40 \text {, with higher } \\
\text { scores indicating } \\
\text { higher satisfaction } \\
\text { with patient- } \\
\text { provider } \\
\text { communication }\end{array}$ \\
\hline $\begin{array}{l}\text { AASPIRE Health } \\
\text { and Healthcare } \\
\text { Self-Efficacy Scale } \\
\text { (HHSES-21) }\end{array}$ & $\begin{array}{l}\text { The following set of questions ask about how confident you are in doing tasks } \\
\text { related to your health and healthcare, with help from others if needed. } \\
\text { 1. How confident are you that you can make an appointment with your } \\
\text { healthcare provider when needed? } \\
\text { 2. How confident are you that you can make it to a scheduled healthcare } \\
\text { appointment? } \\
\text { 3. How confident are you that you can bring what is needed to a healthcare } \\
\text { visit? } \\
\text { 4. How confident are you that you can feel prepared at a healthcare visit? } \\
\text { 5. How confident are you that you can get the accommodations you need for a } \\
\text { successful healthcare visit? }\end{array}$ & $\begin{array}{l}\text { 10-point Likert } \\
\text { scale with } \\
\text { anchors of } \\
\text { "1=Not at all } \\
\text { Confident" to } \\
\text { "10=Totally } \\
\text { confident." }\end{array}$ & $\begin{array}{l}\text { There are two } \\
\text { subscales. The } \\
\text { Individual Level } \\
\text { Self-Efficacy } \\
\text { Subscale consists } \\
\text { of items } 1,2,3,4, \\
11,13,14,15,16, \\
\text { and } 17 . \text { The } \\
\text { Relationship } \\
\text { Dependent Self- } \\
\text { Efficacy Subscale } \\
\text { consists of items }\end{array}$ \\
\hline
\end{tabular}


Instruments to Assess Healthcare Interventions

\begin{tabular}{|c|c|c|}
\hline & $\begin{array}{l}\text { 6. How confident are you that you can describe your symptoms or healthcare } \\
\text { concerns to your provider? } \\
\text { 7. How confident are you that you can answer your healthcare provider's } \\
\text { 8. How confident are you that you can understand what your healthcare } \\
\text { provider tells you about your health? } \\
\text { 9. How confident are you that you can communicate effectively with } \\
\text { your healthcare provider? } \\
\text { 10. How confident are you that you can be open with } \\
\text { your healthcare provider about your feelings or concerns? } \\
\text { 11. How confident are you that you can handle (physically and/or } \\
\text { emotionally) physical examinations, medical tests, or procedures? } \\
\text { 12. How confident are you that you can take part in healthcare decisions? } \\
\text { 13. How confident are you that you can make it through a healthcare visit } \\
\text { without a meltdown, shut-down, or severe anxiety? } \\
\text { 14. How confident are you that you can take medications the way you are } \\
\text { supposed to take them? } \\
\text { 15. How confident are you that you can do what is needed to follow-up after a } \\
\text { visit (for example, make another appointment, get tests done, see a } \\
\text { specialist, go to the pharmacy)? } \\
\text { 16. How confident are you that you can do what is needed to be as healthy as } \\
\text { possible? For example, eat a healthy diet, exercise, relax, or brush your } \\
\text { teeth. } \\
\text { 17. How confident are you that you can do what is needed to take care of your } \\
\text { health conditions (if you have any)? } \\
\text { 18. How confident are you that your provider will understand the role you want } \\
\text { your supporter to play in your healthcare, if applicable? } \\
\text { 19. How confident are you that you can change healthcare providers if you want } \\
\text { to? } \\
\text { 20. How confident are you that you can advocate or speak up for yourself? }\end{array}$ & $\begin{array}{l}5,6,7,8,9,10,12, \\
18,19,20, \text { and } 21 . \\
\text { Each subscale is } \\
\text { scored by } \\
\text { summing } \\
\text { responses to the } \\
\text { items, and then } \\
\text { dividing the sum } \\
\text { by the number of } \\
\text { items. The } \\
\text { resulting subscales } \\
\text { have a possible } \\
\text { range of } 1-10, \\
\text { with higher scores } \\
\text { corresponding to } \\
\text { higher self- } \\
\text { efficacy. }\end{array}$ \\
\hline
\end{tabular}


Instruments to Assess Healthcare Interventions

\begin{tabular}{|c|c|c|c|}
\hline & $\begin{array}{l}\text { 21. How confident are you that you can find reliable sources of information } \\
\text { about your health and health conditions? }\end{array}$ & & \\
\hline $\begin{array}{l}\text { AASPIRE Visit } \\
\text { Preparedness } \\
\text { Scale (VPS-6) }\end{array}$ & $\begin{array}{l}\text { For the next set of questions, think of the last time you went to see your primary } \\
\text { care provider. Please rate how strongly you agree with each statement. } \\
\text { 1. I brought everything I needed with me to the appointment, including } \\
\text { anything that I was asked to bring or wanted to bring. } \\
\text { 2. I came prepared with a list of the most important topics I wanted to discuss. } \\
\text { 3. I was ready to describe my symptoms or concerns. } \\
\text { 4. I was prepared to answer my primary care provider's questions. } \\
\text { 5. I knew what to expect from my appointment. } \\
\text { 6. I knew what to expect from my primary care provider. }\end{array}$ & $\begin{array}{l}\text { Strongly disagree } \\
=1 ; \text { disagree }=2 ; \\
\text { neither agree nor } \\
\text { disagree }=3 ; \\
\text { agree }=4 ; \\
\text { strongly agree = } \\
5\end{array}$ & $\begin{array}{l}\text { The scale is scored } \\
\text { by summing } \\
\text { responses to the } 6 \\
\text { items. It has a } \\
\text { range of 6-30, } \\
\text { with higher scores } \\
\text { indicating higher } \\
\text { visit } \\
\text { preparedness. }\end{array}$ \\
\hline $\begin{array}{l}\text { AASPIRE } \\
\text { Healthcare } \\
\text { Accommodations } \\
\text { Scale (HAS-8) }\end{array}$ & $\begin{array}{l}\text { The next section asks about healthcare accommodations. Healthcare } \\
\text { accommodations are changes to the usual ways of doing things that may help a } \\
\text { person with a disability get better health care. } \\
\text { 1. My clinic makes the accommodations I need to set and keep appointments. } \\
\text { 2. My clinic makes the accommodations I need to handle the waiting room. } \\
\text { 3. My providers and their staff make the accommodations I need to stay calm } \\
\text { and comfortable during a visit. } \\
\text { 4. My providers and their staff make the accommodations I need } \\
\text { to communicate what I wish to say. } \\
\text { 5. My providers and their staff make the accommodations I need to understand } \\
\text { what they are saying. } \\
\text { 6. My providers and their staff make the accommodations I need to handle } \\
\text { 7. My providers and their staff make the accommodations I need to take part in } \\
\text { my own healthcare decisions. } \\
\text { My providers and their staff make the accommodations I need to follow their } \\
\text { Additional open-ended items (not scored) } \\
\text { 9. What healthcare accommodations, if any, do you get? }\end{array}$ & $\begin{array}{l}\text { Strongly disagree } \\
=1 ; \text { disagree }=2 ; \\
\text { neither agree nor } \\
\text { disagree }=3 \text {; } \\
\text { agree }=4 \text {; strongly } \\
\text { agree }=5 .\end{array}$ & $\begin{array}{l}\text { The scale is scored } \\
\text { by summing } \\
\text { responses from } \\
\text { the eight items. } \\
\text { The resulting scale } \\
\text { can range from } 8 \\
\text { to } 40 \text {, with higher } \\
\text { scores indicating } \\
\text { higher use of } \\
\text { accommodations. }\end{array}$ \\
\hline
\end{tabular}


Instruments to Assess Healthcare Interventions

\begin{tabular}{|c|c|c|}
\hline & $\begin{array}{l}\text { 10. What additional healthcare accommodations, if any, would you like to get in } \\
\text { the future (that you don't get now)? }\end{array}$ & \\
\hline \multicolumn{3}{|c|}{ Checklists } \\
\hline $\begin{array}{l}\text { Barriers to } \\
\text { Healthcare } \\
\text { Checklist- Short } \\
\text { Form }\end{array}$ & $\begin{array}{l}\text { The next section has a list of statements. Each statement describes a possible bar } \\
\text { sometimes prevent people from getting good healthcare. } \\
\text { Which of the following barriers keep you from receiving good healthcare? (Select } \\
\text { a. I do not have a way to get to my doctor's office. } \\
\text { b. It is too difficult to make appointments. } \\
\text { c. I have problems filling out paperwork. } \\
\text { d. I find it hard to handle the waiting room. } \\
\text { e. Sensory discomforts (for example, the lights, smells or sounds) get in the } \\
\text { f. I cannot find a healthcare provider who will accommodate my needs. } \\
\text { g. I have inadequate social, family, or caregiver support. } \\
\text { h. I don't understand the healthcare system. } \\
\text { i. Fear, anxiety, embarrassment, or frustration keeps me from getting prima } \\
\text { j. I have trouble following up on care (for example, going to pharmacy, takir } \\
\text { at the right time, or making a follow-up appointment). } \\
\text { k. I have difficulty understanding how to translate medical information into } \\
\text { I. I can take to improve my health. } \\
\text { m. Comm I experience pain and/or other physical symptoms, I have difficultie } \\
\text { n. My providers or the staff do not include me in discussions about my healt } \\
\text { o. My behaviors are misinterpreted by my provider or the staff. } \\
\text { p. My providers or the staff do not take my communications seriously. } \\
\text { q. Other } \\
\text { None of the above }\end{array}$ & $\begin{array}{l}\text { The instrument is } \\
\text { scored as a count } \\
\text { of the total } \\
\text { number of } \\
\text { barriers endorsed. } \\
\text { In this study, we } \\
\text { dichotomized } \\
\text { results at the top } \\
\text { quartile to identify } \\
\text { participants with } \\
\text { high barriers to } \\
\text { care (i.e. } 0-3 \\
\text { barriers vs } 4 \text { or } \\
\text { more barriers). }\end{array}$ \\
\hline $\begin{array}{l}\text { Unmet Healthcare } \\
\text { Needs Checklist }\end{array}$ & $\begin{array}{l}\text { During the past } 6 \text { months, was there a time when you felt that you needed one c } \\
\text { types of healthcare, but did not receive it? Check all the types of healthcare you } \\
\text { did not get. } \\
\text { a. Medical care for a physical health problem } \\
\text { b. Preventive healthcare (including routine physical examinations) }\end{array}$ & $\begin{array}{l}\text { In this study, we } \\
\text { dichotomized } \\
\text { results to separate } \\
\text { participants that } \\
\text { did or did not }\end{array}$ \\
\hline
\end{tabular}


Instruments to Assess Healthcare Interventions

\begin{tabular}{|l|l|l|}
\hline & c. Mental healthcare or counseling & have any unmet \\
& d. Dental care (including dental checkups) & healthcare needs \\
& e. Prescription medicines & \\
& f. Eyeglasses or contact lenses & \\
& g. Other [write-in] & hone of the above
\end{tabular}

Notes: * Items shown are from the patient-report version of the scales. Items from the proxy-report versions available upon request.

Hyperlinks: Primary Care Provider: "Your primary care provider is your "regular doctor" (though they can also be nurse practitioners or physicians assistants)." Preventive healthcare: "Preventive healthcare is healthcare that is aimed at early detection and treatment or prevention of disease. Examples of preventive healthcare may include visits where a healthcare worker performs screening tests such as pap smears, mammograms, colonoscopies; draws blood to check a cholesterol level; counsels a patient about diet, exercise, tobacco, or alcohol; or performs a routine physical examination." 
Instruments to Assess Healthcare Interventions

Table 3

Factor Loadings of Items from Healthcare Self-Efficacy Scale on Two Factor Structure

\begin{tabular}{|c|c|c|}
\hline How confident are you that: & $\begin{array}{l}\text { Individual } \\
\text { Healthcare SE }\end{array}$ & $\begin{array}{c}\text { Relationship- } \\
\text { Dependent } \\
\text { Healthcare SE }\end{array}$ \\
\hline $\begin{array}{l}\text {...you can make an appointment with your healthcare provider } \\
\text { when needed? IHSE }\end{array}$ & 0.61 & 0.28 \\
\hline ...you can make it to a scheduled healthcare appointment? ${ }^{\text {IHSE }}$ & 0.53 & 0.18 \\
\hline ...you can bring what is needed to a healthcare visit? ${ }^{\text {IHSE }}$ & 0.57 & 0.40 \\
\hline ...you can feel prepared at a healthcare visit? ${ }^{\text {IHSE }}$ & 0.62 & 0.49 \\
\hline $\begin{array}{l}\text {...you can get the accommodations you need for a successful } \\
\text { healthcare visit? }{ }^{\text {RDHSE* }}\end{array}$ & 0.54 & $0.49 *$ \\
\hline $\begin{array}{l}\text {...you can describe your symptoms or healthcare concerns to your } \\
\text { provider? RDHSE }\end{array}$ & 0.27 & 0.74 \\
\hline ...you can answer your healthcare provider's questions? RDHSE & 0.35 & 0.77 \\
\hline $\begin{array}{l}\text {...you can understand what your healthcare provider tells you } \\
\text { about your health? RDHSE }\end{array}$ & 0.33 & 0.76 \\
\hline $\begin{array}{l}\text {...you can communicate effectively with your healthcare provider? } \\
\text { RDHSE }\end{array}$ & 0.27 & 0.86 \\
\hline $\begin{array}{l}\text {...you can be open with your healthcare provider about your } \\
\text { feelings or concerns? RDHSE }\end{array}$ & 0.29 & 0.70 \\
\hline $\begin{array}{l}\text {...you can handle (physically and/or emotionally) physical } \\
\text { examinations, medical tests, or procedures? }\end{array}$ & 0.53 & 0.24 \\
\hline ...you can take part in healthcare decisions? ${ }^{\text {RDHSE* }}$ & 0.48 & $0.48 *$ \\
\hline $\begin{array}{l}\text {...you can make it through a healthcare visit without a meltdown, } \\
\text { shut-down, or severe anxiety? IHSE }\end{array}$ & 0.48 & 0.28 \\
\hline $\begin{array}{l}\text {...you can take medications the way you are supposed to take } \\
\text { them? }{ }^{\text {IHSE }}\end{array}$ & 0.53 & 0.14 \\
\hline ...you can do what is needed to follow-up after a visit? ${ }^{\text {IHSE }}$ & 0.67 & 0.32 \\
\hline ...you can do what is needed to be as healthy as possible? IHSE & 0.52 & 0.26 \\
\hline $\begin{array}{l}\text {...you can do what is needed to take care of your health conditions } \\
\text { (if you have any)? }{ }^{\text {HSE }}\end{array}$ & 0.58 & 0.41 \\
\hline $\begin{array}{l}\text {...your provider will understand the role you want your supporter } \\
\text { to play in your healthcare, if applicable? RDHSE }\end{array}$ & 0.42 & 0.61 \\
\hline ...you can change healthcare providers if you want? ${ }^{\text {RDHSE* }}$ & 0.35 & $0.35^{*}$ \\
\hline ...you can advocate or speak for yourself? RDHSE & 0.40 & 0.57 \\
\hline $\begin{array}{l}\text {...you can find reliable sources about your health and health } \\
\text { conditions? RDHSE }\end{array}$ & 0.38 & 0.59 \\
\hline
\end{tabular}

Note. Principal Axis Factor Analysis was conducted with Varimax rotation procedure. SE = Self-efficacy.

The shading indicates which scale in which the item was ultimately included.

IHSE These items were ultimately included in the Independent Healthcare Self-Efficacy Subscale.

RDHSE These items were ultimately included in the Relationship-Dependent Healthcare Self-Efficacy

Subscale. 
Instruments to Assess Healthcare Interventions

* These three items loaded similarly on the two factors. Our academic and community partners felt that, conceptually, these items were more closely related to the Relationship-Dependent Healthcare Self-Efficacy Subscale. 
Instruments to Assess Healthcare Interventions

Table 4

Internal Consistency Reliability of Multi-Item Scales

\begin{tabular}{lccc}
\hline \multicolumn{1}{c}{ Scale } & $\begin{array}{c}\text { Full Sample } \\
\text { alpha }\end{array}$ & $\begin{array}{c}\text { Autistic adults } \\
\text { who participated } \\
\text { directly (with or } \\
\text { without support) } \\
\text { alpha }\end{array}$ & $\begin{array}{c}\text { Autistic adults } \\
\text { who participated } \\
\text { via proxy } \\
\text { alpha }\end{array}$ \\
\hline Patient-Provider Communication Scale & 0.94 & 0.94 & 0.93 \\
Visit Preparedness Scale & 0.83 & 0.82 & 0.82 \\
$\begin{array}{l}\text { Healthcare Accommodations Scale } \\
\begin{array}{l}\text { Individual Healthcare Self-Efficacy Subscale } \\
\text { Relationship-Dependent Healthcare Self- }\end{array}\end{array}$ & 0.93 & 0.92 & 0.96 \\
Efficacy Subscale & 0.92 & 0.89 & 0.84 \\
\hline
\end{tabular}


Instruments to Assess Healthcare Interventions

Table 5

Associations between Healthcare Outcome Measures and Potential Intervention Targets

\begin{tabular}{|c|c|c|c|}
\hline \multicolumn{4}{|c|}{ Unmet Healthcare Needs } \\
\hline & $\begin{array}{c}\text { Any unmet } \\
\text { healthcare needs } \\
\text { Mean (SD) }\end{array}$ & $\begin{array}{c}\text { No Unmet } \\
\text { healthcare needs } \\
\text { Mean (SD) }\end{array}$ & p-value \\
\hline Visit preparedness & $23.13(3.91)$ & $24.55(3.87)$ & 0.0061 \\
\hline Use of accommodations & $27.74(6.22)$ & $30.88(5.74)$ & 0.0001 \\
\hline Individual healthcare self-efficacy & $7.23(1.64)$ & $7.98(1.50)$ & 0.0004 \\
\hline Relationship-dependent healthcare self-efficacy & $6.94(1.79)$ & $7.78(1.84)$ & 0.0005 \\
\hline \multicolumn{4}{|c|}{ Barriers to Healthcare } \\
\hline & $\begin{array}{c}>=4 \text { healthcare } \\
\text { barriers } \\
\text { Mean (SD) }\end{array}$ & $\begin{array}{c}\text { 0-3 healthcare } \\
\text { barriers } \\
\text { Mean (SD) }\end{array}$ & $\mathrm{p}$-value \\
\hline Visit preparedness & $21.23(3.79)$ & $24.71(3.60)$ & 0.00001 \\
\hline Use of accommodations & $26.51(5.98)$ & $30.25(5.92)$ & 0.0001 \\
\hline Individual healthcare self-efficacy & $6.53(1.57)$ & $7.98(1.44)$ & 0.00001 \\
\hline Relationship-dependent healthcare self-efficacy & $6.13(1.89)$ & $7.78(1.66)$ & 0.00001 \\
\hline \multicolumn{4}{|c|}{ Satisfaction with Patient Provider Communication } \\
\hline & \multicolumn{2}{|c|}{ Correlation coefficient } & p-value \\
\hline Visit preparedness & \multicolumn{2}{|c|}{0.55} & 0.00001 \\
\hline Use of accommodations & \multicolumn{2}{|c|}{0.52} & 0.00001 \\
\hline Individual healthcare self-efficacy & \multicolumn{2}{|c|}{0.32} & 0.00001 \\
\hline Relationship-dependent healthcare self-efficacy & \multicolumn{2}{|c|}{0.50} & 0.00001 \\
\hline
\end{tabular}


Instruments to Assess Healthcare Interventions

\section{References}

Akobirshoev, I., Mitra, M., Dembo, R., \& Lauer, E. (2019). In-hospital mortality among adults with autism spectrum disorder in the United States: A retrospective analysis of US hospital discharge data. Autism, 1362361319855795.

Barber, C. (2017). Meeting the healthcare needs of adults on the autism spectrum. British Journal of Nursing, 26(7), 420-425.

Blackwell, D., Gentleman, J., Martin, M., Ng, E.,Sanmartin, C., Simile, C. (2004). Joint Canada/United States Survey of Health: Findings and Public-use Microdata File. Retrieved from http://www.statcan.gc.ca/pub/82m0022x/2003001/pdf/4228656-eng.pdf

Brundisini, F., Giacomini, M., DeJean, D., Vanstone, M., Winsor, S., \& Smith, A. (2013). Chronic disease patients' experiences with accessing health care in rural and remote areas: a systematic review and qualitative meta-synthesis. Ontario health technology assessment series, 13(15), 1.

Burns, M. I., Baylor, C., Dudgeon, B. J., Starks, H., \& Yorkston, K. (2017). Health care provider accommodations for patients with communication disorders. Topics in Language Disorders, 37(4), 311-333.

Callaghan, D. M. (2003). Health-promoting self-care behaviors, self-care self-efficacy, and self-care agency. Nursing Science Quarterly, 16(3), 247-254.

Cantor, D., Covell, J., Davis, T., Park, I., \& Rizzo, L. . (2009). Health Information National Trends Survey (HINTS). Retrieved from http://hints.cancer.gov/docs/HINTS2007FinalReport.pdf

Clay, O. J., \& Telfair, J. (2007). Evaluation of a disease-specific self-efficacy instrument in adolescents with sickle cell disease and its relationship to adjustment. Child Neuropsychology, 13(2), 188203.

Croen, L. A., Zerbo, O., Qian, Y., Massolo, M. L., Rich, S., Sidney, S., \& Kripke, C. (2015). The health status of adults on the autism spectrum. Autism, 19(7), 814-823.

Deblonde, J., De Koker, P., Hamers, F. F., Fontaine, J., Luchters, S., \& Temmerman, M. (2010). Barriers to HIV testing in Europe: a systematic review. European Journal of Public Health, 20(4), 422-432.

Du, S., \& Yuan, C. (2010). Evaluation of patient self-management outcomes in health care: a systematic review. International nursing review, 57(2), 159-167.

Fortuna, R. J., Robinson, L., Smith, T. H., Meccarello, J., Bullen, B., Nobis, K., \& Davidson, P. W. (2016). Health Conditions and Functional Status in Adults with Autism: A Cross-Sectional Evaluation. Journal of General Internal Medicine, 31(1), 77-84.

Gibson, O., Lisy, K., Davy, C., Aromataris, E., Kite, E., Lockwood, C., . . Brown, A. (2015). Enablers and barriers to the implementation of primary health care interventions for Indigenous people with chronic diseases: a systematic review. Implementation Science, 10(1), 71.

Green, S. B., \& Salkind, N. J. (2013). Using SPSS for Windows and Macinstosh (7th Ed.(Upper Saddle River, NJ: Pearson Education, Inc.

Hacker, K., Anies, M., Folb, B. L., \& Zallman, L. (2015). Barriers to health care for undocumented immigrants: a literature review. Risk management and healthcare policy, 8, 175.

Hall, T., Kriz, D., Duvall, S., Nguyen-Driver, M., \& Duffield, T. (2015). Healthcare transition challenges faced by young adults with autism spectrum disorder. Clinical Pharmacology \& Therapeutics, 98(6), 573-575.

Hirvikoski, T., Mittendorfer-Rutz, E., Boman, M., Larsson, H., Lichtenstein, P., \& Bölte, S. (2016). Premature mortality in autism spectrum disorder. British Journal of Psychiatry, 208(03), 232238. doi:10.1192/bjp.bp.114.160192 
Instruments to Assess Healthcare Interventions

Holman, D. M., Benard, V., Roland, K. B., Watson, M., Liddon, N., \& Stokley, S. (2014). Barriers to human papillomavirus vaccination among US adolescents: a systematic review of the literature. JAMA pediatrics, 168(1), 76-82.

Hong, T. (2008). Internet Health Information in the Patient-Provider Dialogue. CyberPsychology \& Behavior(5), 587-589.

Hutcheson, G. D., \& Sofroniou, N. (1999). The multivariate social scientist: Introductory statistics using generalized linear models: Sage.

Khatib, R., Schwalm, J.-D., Yusuf, S., Haynes, R. B., McKee, M., Khan, M., \& Nieuwlaat, R. (2014). Patient and healthcare provider barriers to hypertension awareness, treatment and follow up: a systematic review and meta-analysis of qualitative and quantitative studies. PloS one, 9(1), e84238.

Liu, G., Pearl, A. M., Kong, L., Leslie, D. L., \& Murray, M. J. (2017). A profile on emergency department utilization in adolescents and young adults with autism spectrum disorders. Journal of autism and developmental disorders, 47(2), 347-358.

Marks, R., Ok, H., Joung, H., \& Allegrante, J. P. (2010). Perceptions about collaborative decisions: perceived provider effectiveness among 2003 and 2007 Health Information National Trends Survey (HINTS) respondents. Journal of Health Communication, 15 Suppl 3, 135-146.

Mason, D., Ingham, B., Urbanowicz, A., Michael, C., Birtles, H., Woodbury-Smith, M., . . Nicolaidis, C. (2019). A Systematic Review of What Barriers and Facilitators Prevent and Enable Physical Healthcare Services Access for Autistic Adults. Journal of autism and developmental disorders, 114.

Mokkink, L. B., Terwee, C. B., Patrick, D. L., Alonso, J., Stratford, P. W., Knol, D. L., . . de Vet, H. C. (2010). The COSMIN study reached international consensus on taxonomy, terminology, and definitions of measurement properties for health-related patient-reported outcomes. Journal of Clinical Epidemiology, 63(7), 737-745.

Nicolaidis, C., Kripke, C. C., \& Raymaker, D. (2014). Primary care for adults on the autism spectrum. Medical Clinics of North America, 98(5), 1169-1191. doi:https://doi.org/10.1016/j.mcna.2014.06.011

Nicolaidis, C., Raymaker, D., Kapp, S. K., Baggs, A., Ashkenazy, E., McDonald, K., . . Joyce, A. (2019). The AASPIRE practice-based guidelines for the inclusion of autistic adults in research as coresearchers and study participants. Autism, 23(8), 2007-2019. doi:https://doi.org/10.1177/1362361319830523

Nicolaidis, C., Raymaker, D., McDonald, K., Dern, S., Ashkenazy, E., Boisclair, C., . . Baggs, A. (2011). Collaboration strategies in nontraditional community-based participatory research partnerships: lessons from an academic-community partnership with autistic self-advocates. Progress in Community Health Partnerships, 5(2), 143-150. doi:https://doi.org/10.1353/cpr.2011.0022

Nicolaidis, C., Raymaker, D., McDonald, K., Dern, S., Boisclair, W. C., Ashkenazy, E., \& Baggs, A. (2013). Comparison of healthcare experiences in autistic and non-autistic adults: A cross-sectional online survey facilitated by an academic-community partnership. Journal of General Internal Medicine, 28(6), 761-769. doi:https://doi.org/10.1007/s11606-012-2262-7

Nicolaidis, C., Raymaker, D., McDonald, K., Kapp, S., Weiner, M., Ashkenazy, E., . . Baggs, A. (2016). The Development and Evaluation of an Online Healthcare Toolkit for Autistic Adults and their Primary Care Providers. Journal of General Internal Medicine, 31(10), 1180-1189. doi:https://doi.org/10.1007/s11606-016-3763-6

Nicolaidis, C., Raymaker, D. M., Ashkenazy, E., McDonald, K. E., Dern, S., Baggs, A. E., . . Boisclair, W. C. (2015). "Respect the way I need to communicate with you": Healthcare experiences of adults on the autism spectrum. Autism, 19(7), 824-831. doi:https://doi.org/10.1177/1362361315576221 
Instruments to Assess Healthcare Interventions

Ok, H., Marks, R., \& Allegrante, J. P. (2008). Perceptions of health care provider communication activity among American cancer survivors and Adults Without Cancer Histories: an analysis of the 2003 Health Information Trends Survey (HINTS) Data. Journal of Health Communication, 13(7), 637653.

Pharr, J. R. (2014). Accommodations for patients with disabilities in primary care: a mixed methods study of practice administrators. Global journal of health science, 6(1), 23.

Pharr, J. R., James, T., \& Yeung, Y.-L. (2019). Accessibility and accommodations for patients with mobility disabilities in a large healthcare system: How are we doing? Disability and health journal.

Raymaker, D. M., McDonald, K. E., Ashkenazy, E., Gerrity, M., Baggs, A. M., Kripke, C., . . Nicolaidis, C. (2017). Barriers to healthcare: Instrument development and comparison between autistic adults and adults with and without other disabilities. Autism, 21(8), 972-984. doi:https://doi.org/10.1177/1362361316661261

Sanmartin, C., Berthelot, J.-M., Ng, E., Murphy, K., Blackwell, D. L., Gentleman, J. F., . . S Simile, C. M. (2006). Comparing Health And Health Care Use In Canada And The United States. Health Aff, 25(4), 1133-1142. doi:10.1377/hlthaff.25.4.1133

Shively, M., Smith, T. L., Bormann, J., \& Gifford, A. L. (2002). Evaluating self-efficacy for HIV disease management skills. AIDS and Behavior, 6(4), 371-379.

Stevens, J. P. (2012). Applied multivariate statistics for the social sciences: Routledge.

Stewart, M. A. (1995). Effective physician-patient communication and health outcomes: a review. CMAJ: Canadian Medical Association Journal, 152(9), 1423.

U.S. Department of Health and Human Services. (2017). Report to Congress: Young Adults and Transitioning Youth with Autism Spectrum Disorder. Retrieved from https://www.hhs.gov/sites/default/files/2017AutismReport.pdf

Vohra, R., Madhavan, S., \& Sambamoorthi, U. (2016). Emergency Department Use Among Adults with Autism Spectrum Disorders (ASD). Journal of autism and developmental disorders, 46(4), 14411454. doi:10.1007/s10803-015-2692-2

Zerbo, O., Massolo, M. L., Qian, Y., \& Croen, L. A. (2015). A Study of Physician Knowledge and Experience with Autism in Adults in a Large Integrated Healthcare System. Journal of autism and developmental disorders, 45(12), 4002-4014.

Zerbo, O., Qian, Y., Ray, T., Sidney, S., Rich, S., Massolo, M., \& Croen, L. A. (2019). Health care service utilization and cost among adults with autism spectrum disorders in a US integrated health care system. Autism in Adulthood, 1(1), 27-36. 